\title{
INTEGRAL REPRESENTATIONS AND INEQUALITIES OF EXTENDED CENTRAL BINOMIAL COEFFICIENTS
}

\author{
Chunfu Wei ${ }^{1}$ \\ ${ }^{1}$ School of Mathematics and Informatics, Henan Polytechnic University
}

October 6, 2021

\begin{abstract}
In the paper, the author presents three integral representations of extended central binomial coefficient, proves decreasing and increasing properties of two power-exponential functions involving extended (central) binomial coefficients, derives several double inequalities for bounding extended (central) binomial coefficient, and compares with known results.
\end{abstract}

\section{Hosted file}

DIGCBC-Wei.pdf available at https://authorea.com/users/439871/articles/540681-integralrepresentations-and-inequalities-of-extended-central-binomial-coefficients 